\title{
AN EXPERIMENTAL STUDY OF SEVERAL METHODS OF REPRESENTING PHOTOGRAPHIC SENSITIVITY
}

\author{
By Raymond Davis and Gerald Kent Neeland
}

ABSTRACT

The relation between photographic sensitivity and the amount of development has been studied using as indices of sensitivity three modifications of Hurter and Driffield's method of measuring plate speeds. The results are generally in accord with those of Bullock, who investigated the relation of threshold speed to development time. An optimum time of development is indicated which varies with the type of emulsion considered.

The study brought out the differences between the three indices considered and led to the conclusion that no single value is adequate to represent the sensitivity of a given emulsion. ' It is more satisfactory to represent the sensitivity of an emulsion in terms of a curve plotted between a sensitivity index and development time.

\section{CONTENTS}

I. Introduction

II. Methods of measuring sensitivity _...

III. Experimental results

IV. Discussion of results........ 509

1. Characteristics of the three methods......... 509

2. Method of expressing relative sensitivity

3. Summary _.

\section{INTRODUCTION}

Several ways of measuring the sensitivity of photographic emulsions have been proposed from time to time. At first sensitivity or "speed" was taken as inversely proportional to the exposure required to produce (on development) a just perceptible image. This has been called threshold speed. The difficulty in specifying accurately a "just perceptible" density discouraged the use of the method, although modifications are still employed to some extent.

In 1890 Hurter and Driffield began their series of papers describing a new system of representing characteristics of photographic plates. The basis of this system was a "characteristic curve" representing density as a function of log exposure. The exposure value of the intersection of an extension of the straight line portion of this curve with the base line was called the "inertia" of the plate. The "speed" of the plate was taken as proportional to the reciprocal of the inertia.

They found that (in the absence of soluble bromides) these plate speeds were constant for a given plate regardless of the time of development. In other words, extensions of the straight line portions of the characteristic curves met at a point on the exposure axis. In the work at this laboratory during the past 20 years an emulsion has rarely been found giving a family of curves such that extensions of the straight line portions met at a point on the exposure axis. 
Neitz, ${ }^{1}$ in 1920 , after an extended study, found that the extensions of the straight line portions of characteristic curves, plotted on a basis of total densities (instead of the total density minus fog density basis used by Hurter and Driffield), for several times of development, intersected at a point. The location of this point was on or below the axis, depending on the plate and developer used.

More recently, others have been unable to find a common intersection point for extensions of the straight line portions of a family of characteristic curves either when plotted on a total density or a total density minus fog density basis. This discrepancy between the results of Hurter and Driffield and those of later workers is thought to be due to changes in the methods of manufacturing emulsions.

Bullock ${ }^{2}$ investigated the relation between threshold speed (using a Chapman Jones plate tester) and development time. He obtained curves indicating an optimum time of development.

The present paper gives the results of an experimental investigation of the characteristics of several types of emulsions undertaken to determine the relative merits of three modifications of Hurter and Driffield's method of expressing sensitivity and to observe the influence of the amount of development on sensitivity.

\section{METHODS OF MEASURING SENSITIVITY}

As previously stated, Hurter and Driffield ${ }^{3}$ took as a measure of sensitivity a quantity proportional to the reciprocal of the inertia $i$. Inertia was defined as the exposure value of the intersection of an extension of the straight line portion of the characteristic curve with the base line. They considered density to be the difference between the total density of the deposit and that density due to glass, gelatin, and fog (here termed fog density). This is equivalent to plotting total density against log exposure and taking inertia as the exposure value of the intersection of an extension of the straight line portion of the characteristic curve with a horizontal line representing the fog density on an unexposed portion of the same sample.

For an emulsion having a straight line characteristic over the exposure range under consideration this is a very satisfactory method of expressing sensitivity because it is possible to calculate the density for any exposure within this range from the following relation:

where

$$
D=\gamma(\log E-\log i)
$$

$D=$ total density minus fog density;

$\gamma=$ slope of straight line portion;

and

$E=$ exposure;

$i=$ inertia.

Unfortunately, emulsions in present use give characteristic curves which seldom possess a central straight portion. It is necessary, therefore, to adopt some other method in these cases.

${ }^{1}$ A. H. Neitz, The Theory of Development, Monographs on the Theory of Photography No. 2 from the Research Laboratory of the Eastman Kodak Co.

2 E. R. Bullock, On Variations in Threshold Speed According to the Developer and Conditions of Development, I and II, Comm. No. 268, Abridged Scientific Publications, Research Laboratory, Eastman Kodak Co., p. 144: 1926.

F. Furter and V. C. Driffield, The Burler and Driffeld System, The Hurter and Driffield Memorial Volume, p. 300 . 
The three different methods of deriving a sensitivity index from the characteristic curve which were considered in the present study are illustrated in Figure 1.

The first method substitutes for the extension of the straight-line portion the tangent to the curve at the point of maximum gradient $(G$ (max.)). The intersection of this tangent with a horizontal line representing the fog density is designated as $\iota$ (iota). The sensitivity index on this basis is $10 / \mathrm{l}$ as shown in the third column of Tables 2 to 6 , inclusive. It should be pointed out that the density for a given exposure value can be calculated from either $\iota$ or $i$ only over the straight portion of the characteristic curve.

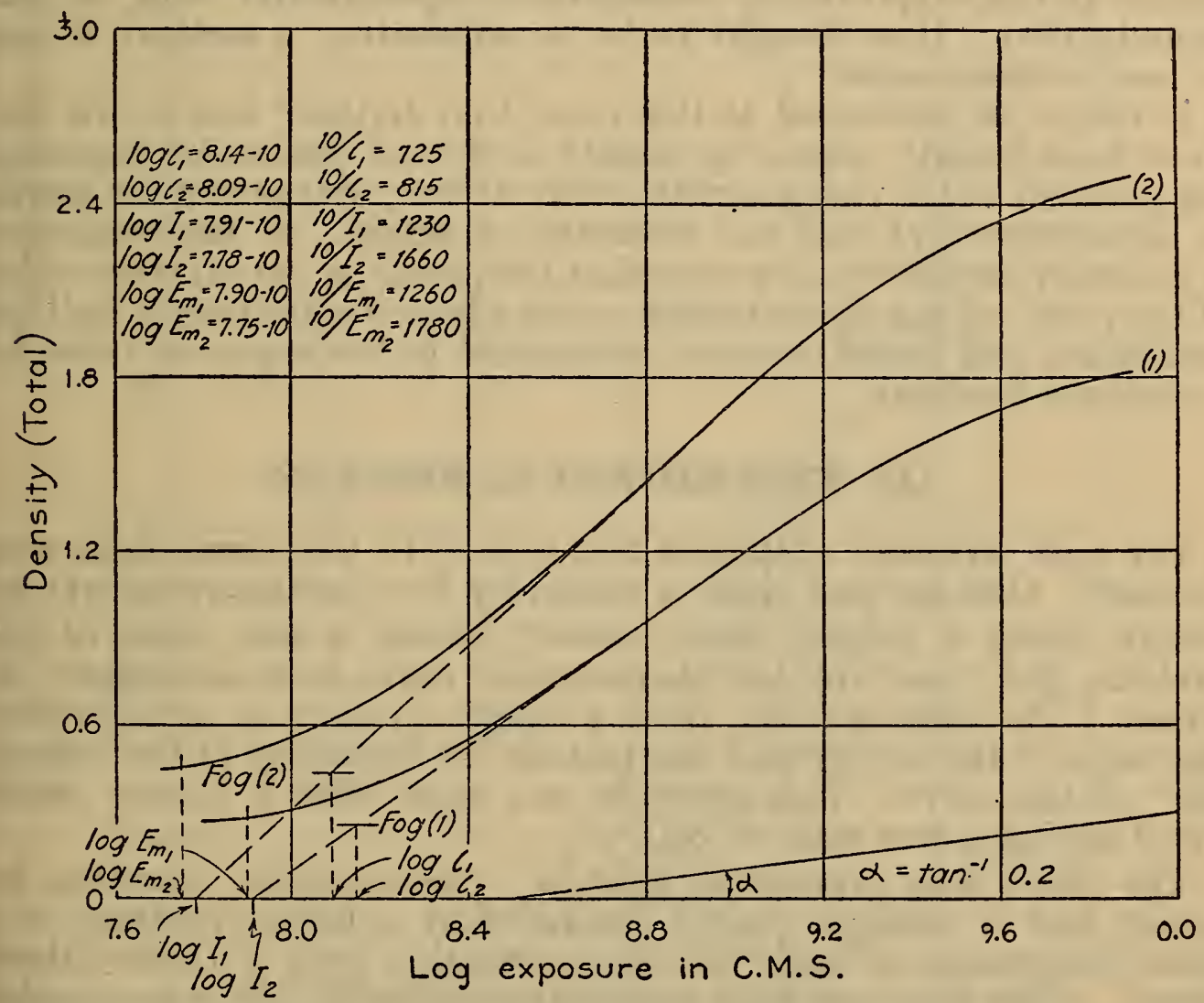

FIGURE 1.-Illustrating the methods of obtaining the three indices of sensitivity from each of two characteristic curves

A method of deriving an index of sensitivity from the characteristic curve which has been frequently used is similar to H. \& D.'s, except, that sensitivity is taken as proportional to the exposure value of the point of intersection of an extension of the straight line portion of the characteristic curve with the zero density axis, on a total density log exposure diagram. This point is sometimes erroneously called the inertia. In the second method used in the present work a quantity, $I$, is defined as the exposure value of the intersection of the tangent to the characteristic curve at the point of maximum gradient with the zero density line. The sensitivity index on this basis is $10 / I$.

It should be noted that $\iota$ will be equal to $i$; and $I$ will be equal to this erroneous inertia when the characteristic curve has a central straight portion. 
The third method of gaging sensitivity studied here is that of Jones and Russell, ${ }^{4}$ who take speed as proportional to the reciprocal of a quantity $E_{\mathrm{m}}$ which is defined as the exposure corresponding to the point in the "toe" region of the characteristic curve where the gradient is 0.20 .

When the characteristic curves are not straight for an appreciable length, or especially when one is dealing with a range of exposures which more than covers the straight line portion (which often occurs in practical photography), the expression of sensitivity in terms of inertia is obviously unsatisfactory. These cases demand some other method. The system proposed by Jones and Russell seems logical and is supported by considerable experimental work on tone reproduction. It is thought to be as satisfactory a method as can be used in these cases.

It might be mentioned at this point that Luther ${ }^{5}$ has shown that when total density minus fog density is plotted against log exposure, the gradient of the characteristic curve at the point above the inertia is (approximately) half the maximum gradient. If his conclusion is generally applicable, it means that the inertia is the exposure value of the point on the characteristic curve where the gradient is half the maximum, and hence does not correspond to the exposure value for a constant gradient.

\section{EXPERIMENTAL RESULTS}

For each emulsion examined two sets of 11 test strips each were exposed. One set was given a relatively low (nonintermittent) exposure, using a 13 -step sector wheel ${ }^{6}$ having a step ratio of $\sqrt{2}$, enabling the "toe" of the characteristic curve to be accurately obtained. The other set was given a longer exposure so as to overlap the range of the former and also include the beginning of the "shoulder" of the curve. This exposure was made with a 13-step sector wheel having a step ratio of $\sqrt[3]{4}$.

The plates were exposed to light of 1 meter-candle luminous intensity and of sunlight quality, produced by a lamp operating at a color temperature of $2,360^{\circ} \mathrm{K}$. in combination with a Davis-Gibson filter. $^{7}$ (This lamp and filter combination is tentatively recommended as standard by the Seventh International Congress of Photography for use in the sensitometry of negative materials.)

In accordance with customary practice in sensitometric work at this laboratory, the plates were backed, previous to exposure, with a black shellac mixture in order to prevent halation.

The 11 exposed test strips were placed together in a single tray of developer at $20^{\circ} \mathrm{C}$. The strips were removed one at a time at intervals giving development times from 1 to 22 minutes. This more than covered the usual range of development times. Agitation of the developer was secured by brushing the plates with a camels-

4 L. A. Jones and M. E. Russell, The Expression of Plate Speed in Terms of Minimum Useful Gradient, Proc. Seventh Intern. Cong. Photography, p. 130.

8 R. Luther, The Under-exposure Period of the Characteristic Curve, Trans. Far. Soc., 19, p. 340; 1923.

6 For details of the sensitometer used, see, Raymond Davis, A Nonintermittent Sensitometer, B. S. Sci. Papers, No. 511 .

${ }_{7}$ Raymond Davis and K. S. Gibson, Filters for the Reproduction of Sunlight and Daylight and the Determination of Color 'Temperature, B. S. Miscellaneous Publication No. 114. 
hair brush. A. B. C. pyro developer was used according to the following formula:

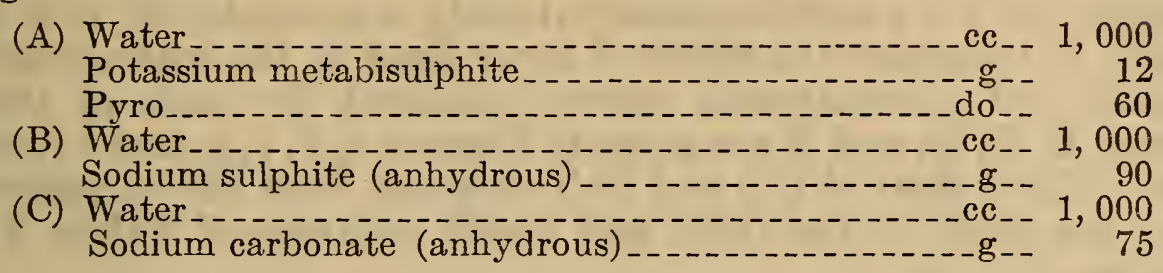

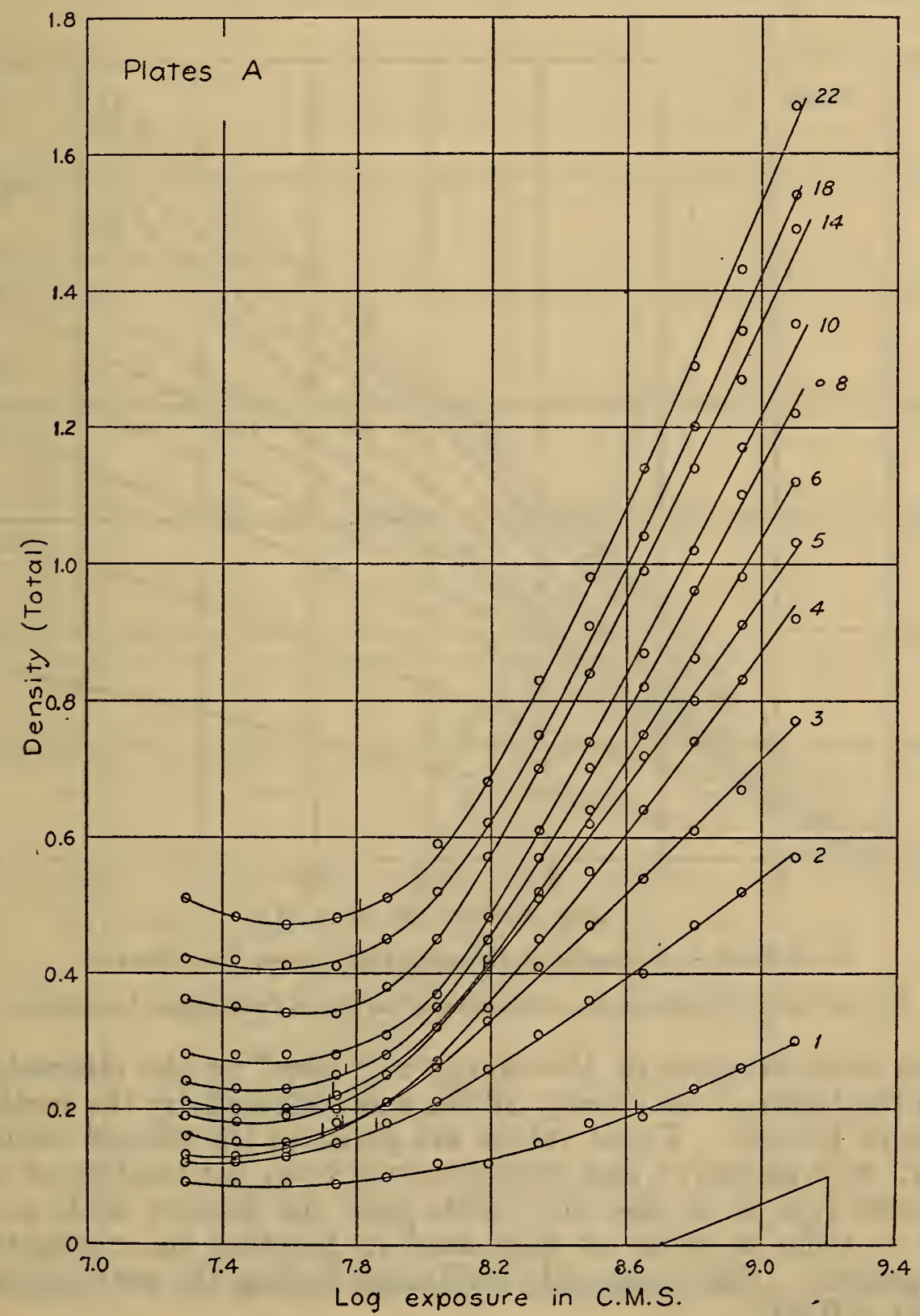

FIgURE 2.-A family of "toes" to the characteristic curves for plates $A$

The numbers at the ends of the curves indicate the time of development in minutes.

To develop, 1 part each of $\mathrm{A}, \mathrm{B}$, and $\mathrm{C}$ was mixed with 7 parts of water: 
Throughout the paper, values of total density are given as read on a Martens polarization photometer ${ }^{8}$ with diffuse illumination. For densities over 1.5 a supplementary density was employed, as is usual, in order to minimize the effect of stray light in the instrument.

Families of characteristic curves obtained for each of the five plates A, B, C, D, and E are given in Figures 3, 5, 7, 9, and 11, respectively. The values of $10 / \iota$ and $10 / I$ obtained from the corresponding curves are given in the third and fourth columns of Tables 2 to 6 , inclusive.

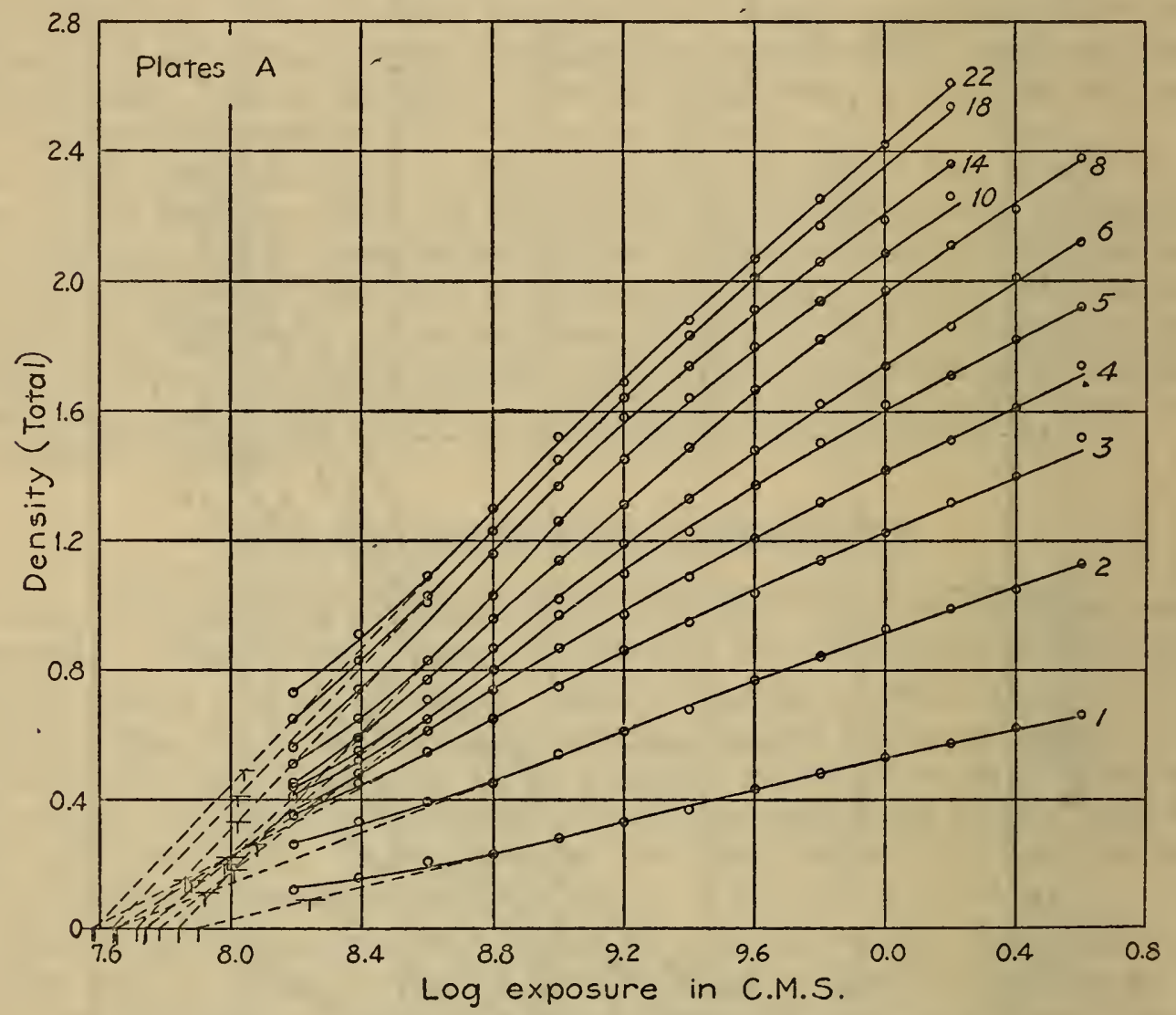

Figure 3.-A family of characteristic curves for plates $A$

The numbers at the ends of the curves indicate the time of development in minutes.

From each member of the family of "toes" to the characteristic curves the index of sensitivity $10 / \mathrm{E}_{m}$ was obtained by the method of Jones and Russell. These values are given in the second column of Tables 2 to 6 , inclusive, and were obtained from the families of curves in Figures 2, 4, 6, 8, and 10 . Note that the density scale in these figures is twice as great as that used in plotting the characteristic curve proper. This large scale facilitated finding the point where the gradient is 0.20 .

It should be pointed out in connection with the characteristic curves (and the "toes"), that the data were plotted as obtained without smoothing. In all cases curves were drawn through the points without anticipating straight line portions. In one or two cases noted in the tables, defective or irregularly developed test strips were en-

${ }^{8}$ Raymond Davis and F. M. Walters, jr., Sensitometry of Photographic Emulsions and a Survey of the Characteristics of Plates and Films of American Mąnufacture, B. S. Sci. Papers No. 439, p. 22 , 


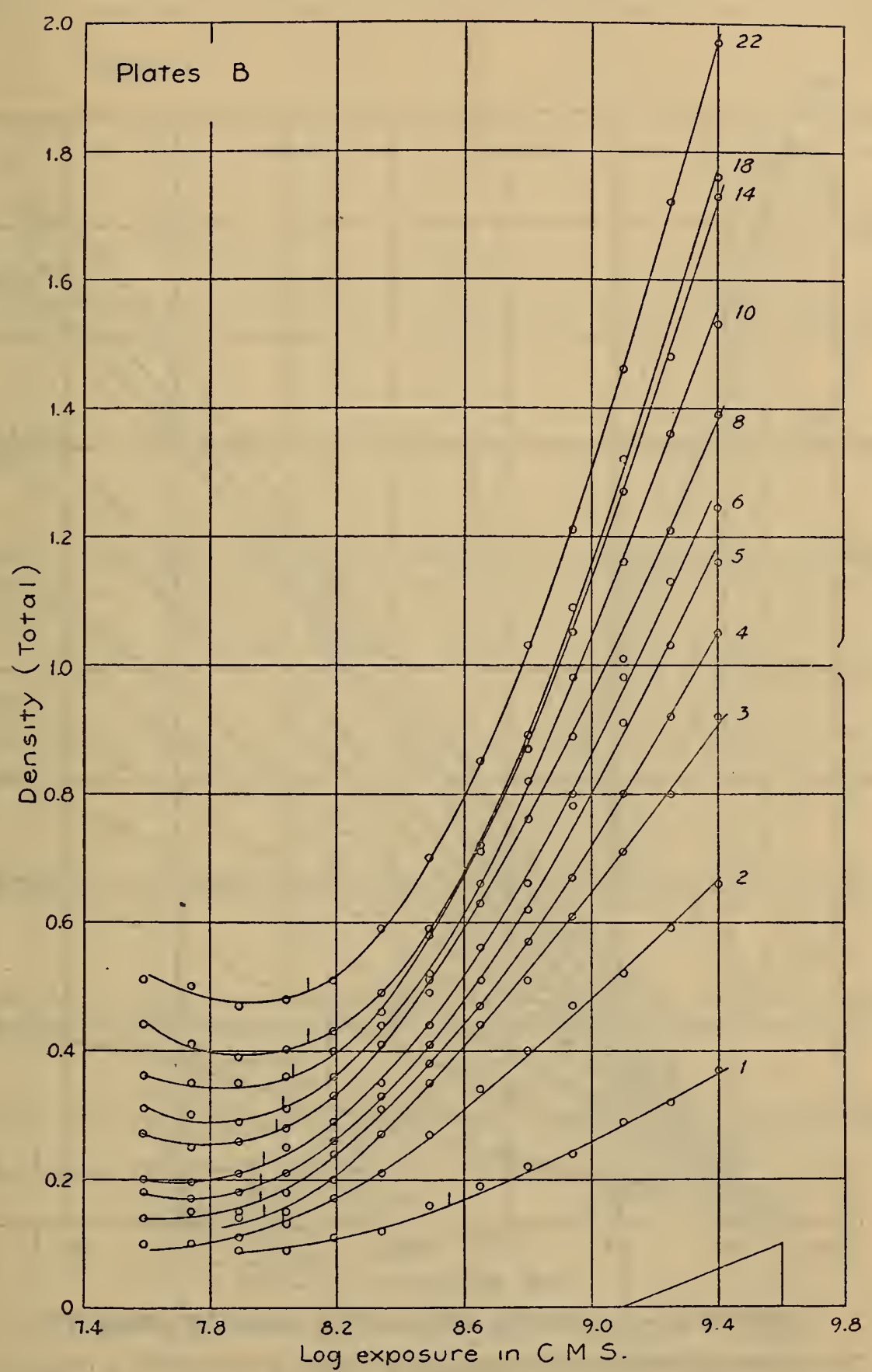

Figdre 4.-A family of "toes" to the characteristic curves for plates $B$

The numbers at the ends of the curves indicate the time of development in minutes. 


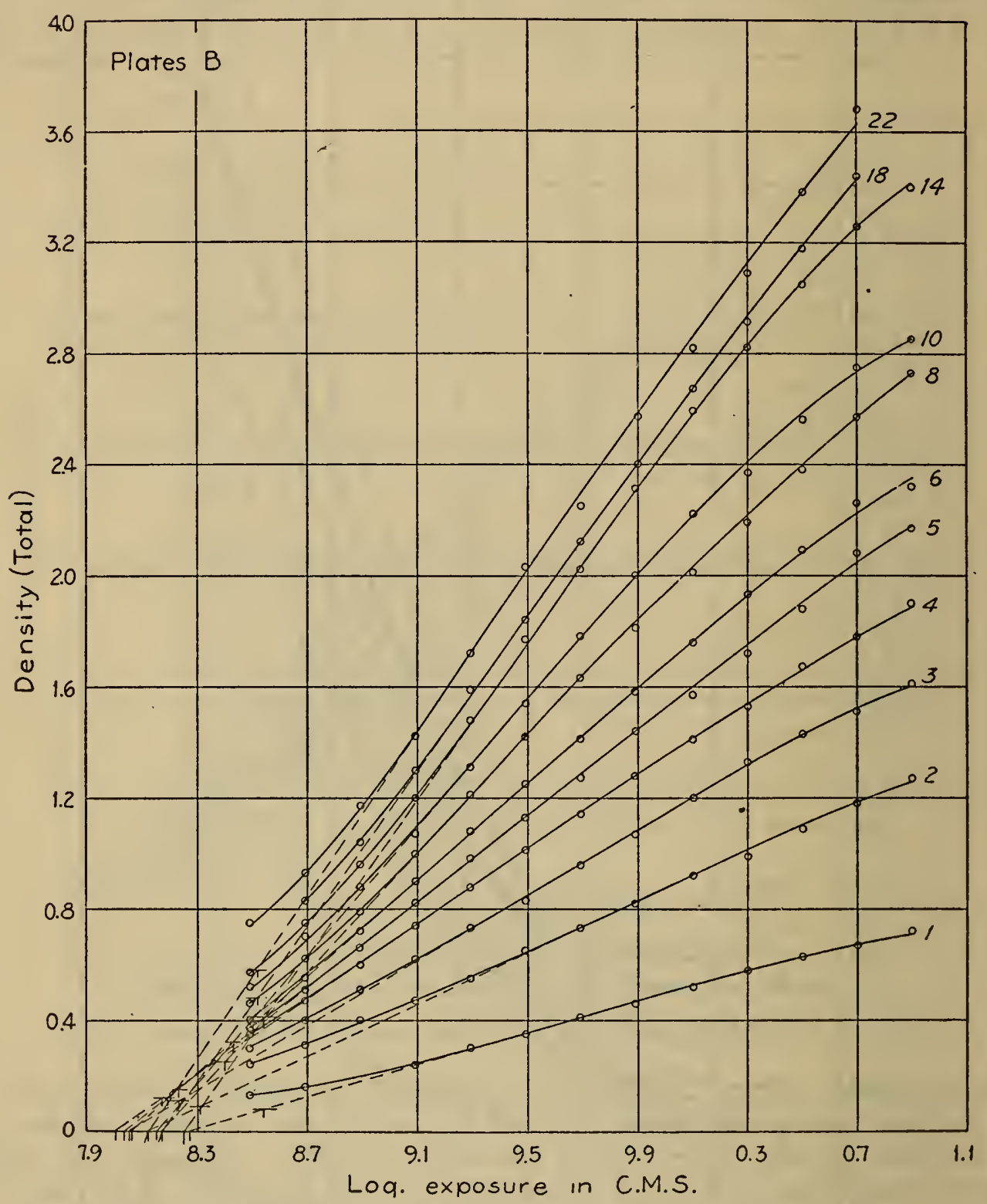

Figdre 5.-A family of characteristic curves for plates $B$

The numbers at the ends of the curves indicate the time of develonment in minutes. 


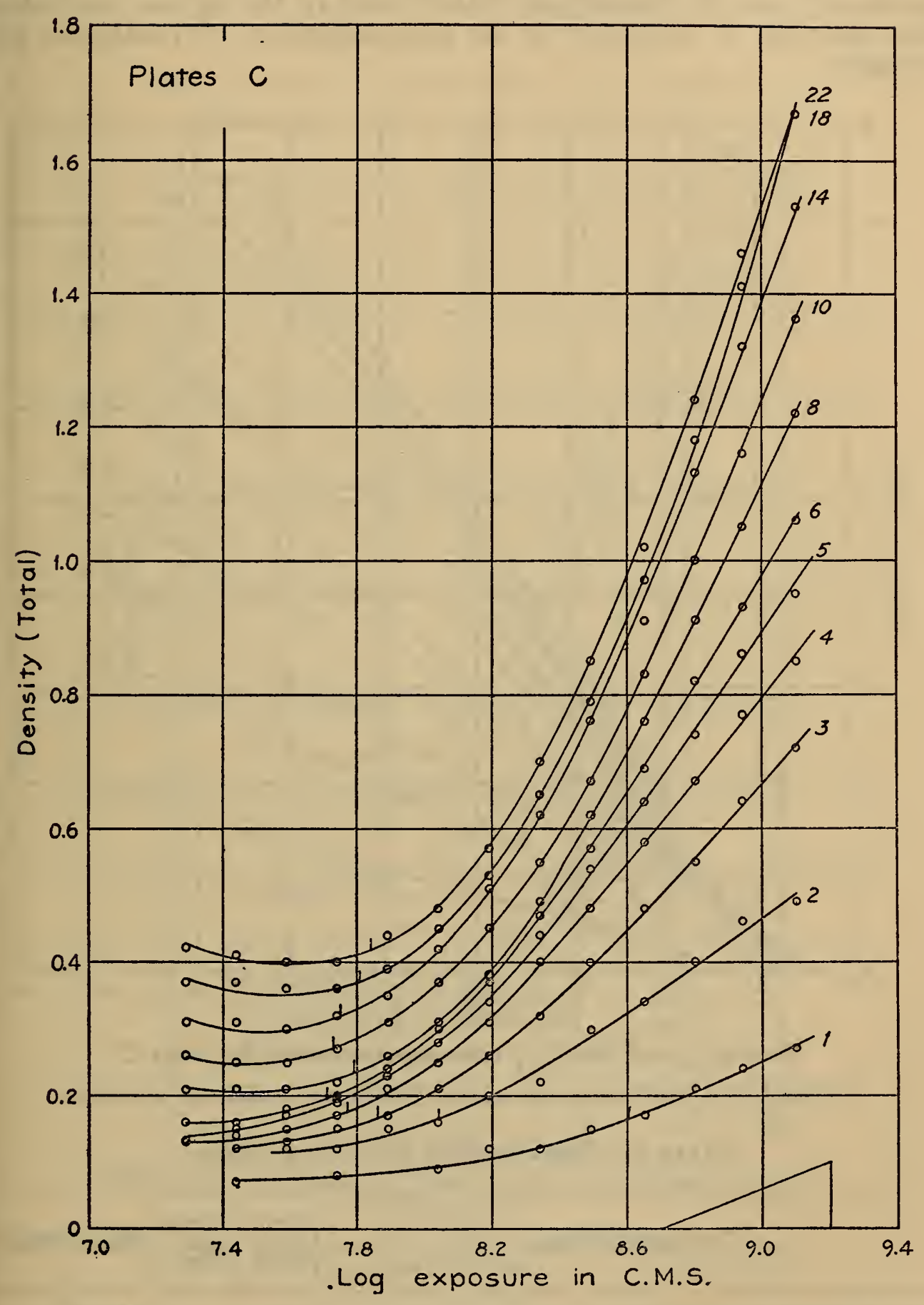

Figure 6.-A family of "toes" to the characteristic curves for plates $C$

The numbers at the ends of the curves indicate the time of development in minutes. 
countered. However, these cases do not influence the corresponding sensitivity, development time curves appreciably.

In Table 1 are listed the plates included in this study, the types of emulsions, and the identifying letters used in the figures and tables. The selection is intended to be representative of emulsions now available.

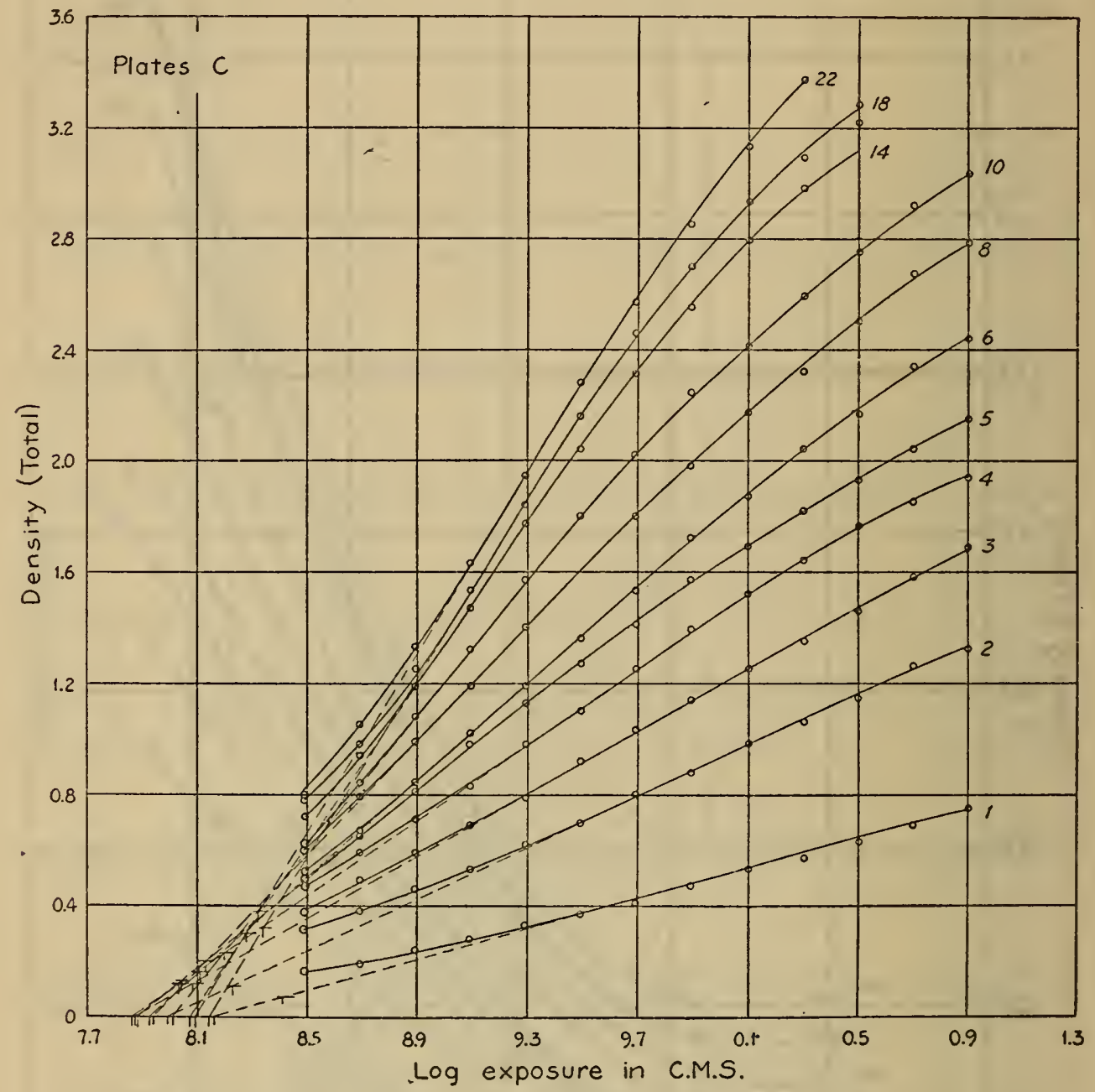

Figure 7.-A family of characteristic curves for plates $C$

The numbers at the ends of the curves indicate the time of development in minutes.

TABLE 1.-Plates included in the investigation

Description of plate

American "speed" orthochromatic

A mericon " medium speed" ordin

German "speed" orthochromatic

English "speed" panchromatic

American "process" ordinary

\begin{tabular}{|r|r|l}
$\begin{array}{c}\text { Identi- } \\
\text { fying } \\
\text { letter }\end{array}$ & $\begin{array}{r}\text { Table } \\
\text { refer- } \\
\text { ence }\end{array}$ & \multicolumn{1}{|l}{ Figure reference } \\
\hline A & 2 & $2,3,12,17$. \\
$\mathrm{B}$ & 3,7 & $4,5,13,17,18,19$. \\
$\mathrm{C}$ & 4 & $6,7,14,17$. \\
$\mathrm{D}$ & 5 & $8,9,15,17$. \\
$\mathrm{E}$ & 6 & $10,11,16$. \\
\hline
\end{tabular}




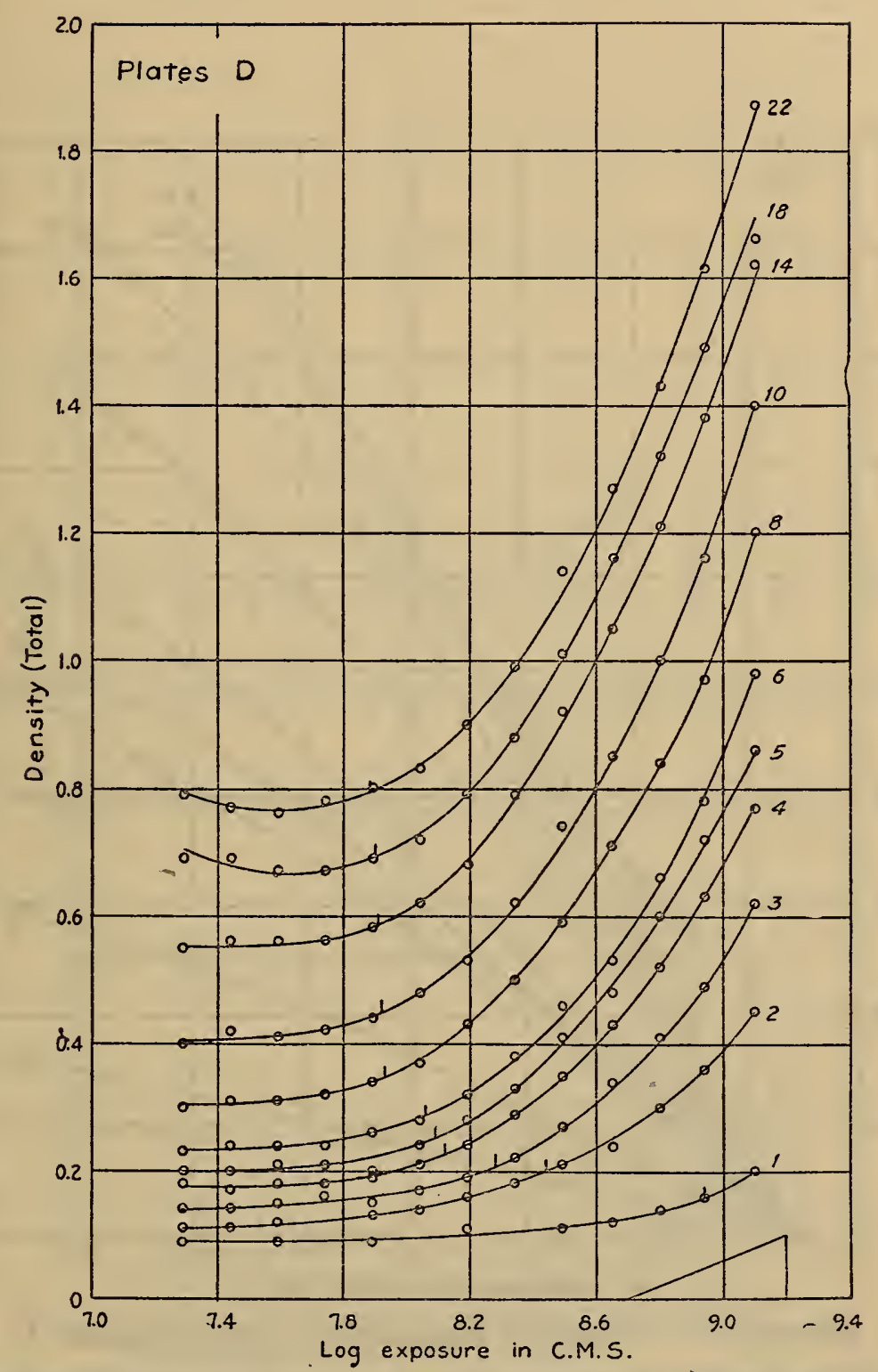

FIGURE 8.-A family of "toes" to the characteristic curves for plates $D$

The numbers at the ends of the curves indicate the time of development in minutes. 


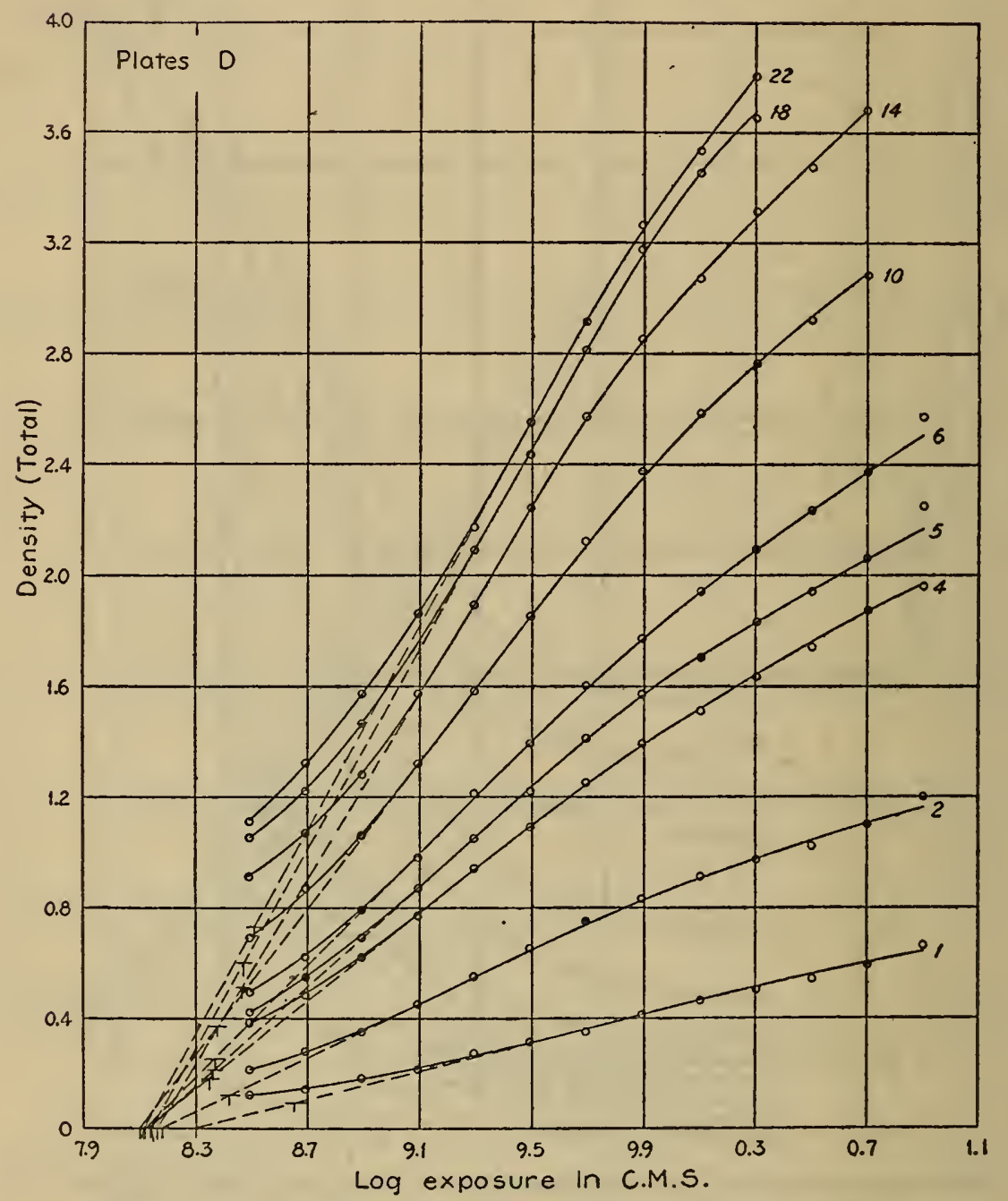

Figure 9.-A family of characteristic curves for plates $D$

The numbers at the ends of the curves indicate the time of development in minutes. 


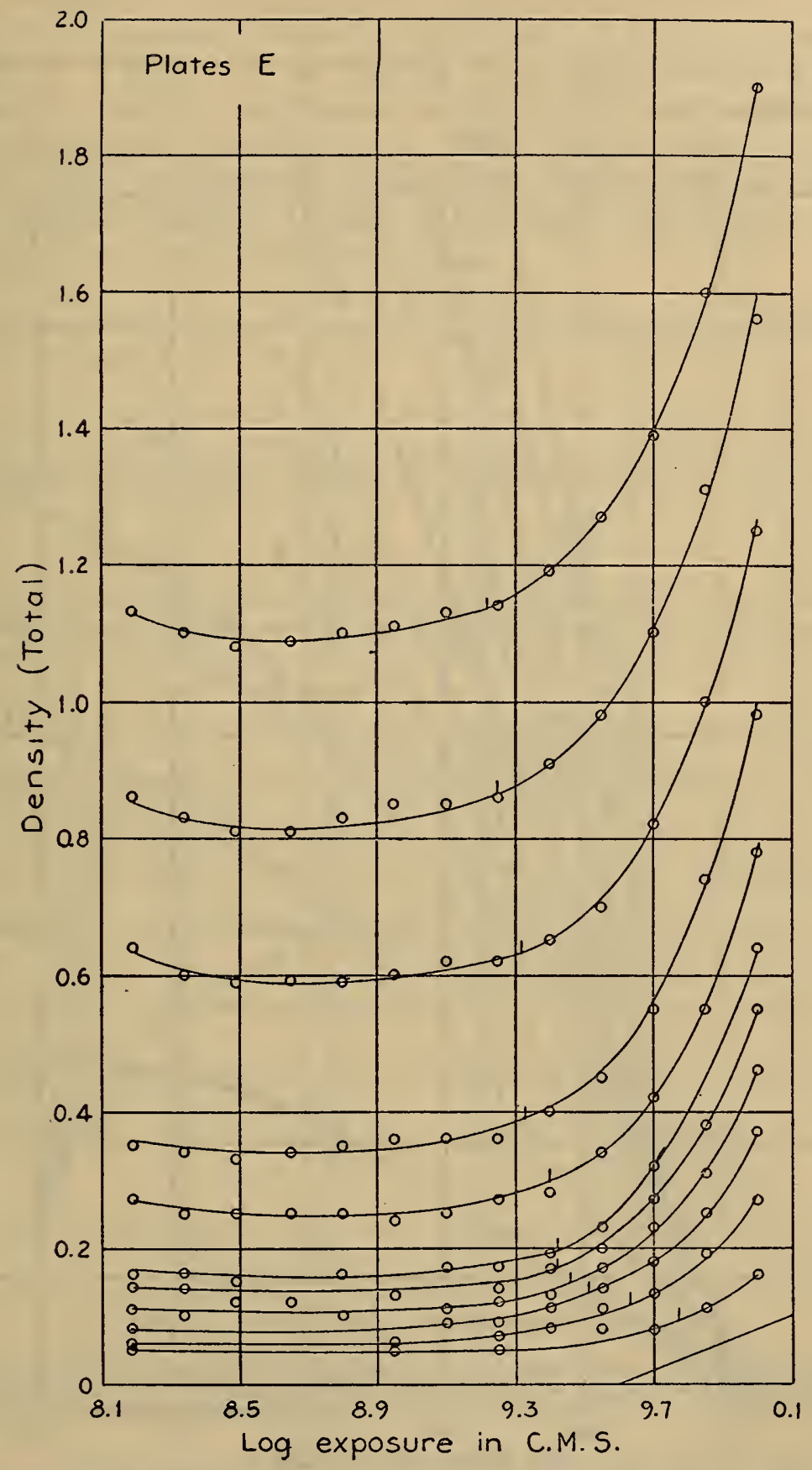

FIgURE 10.-A family of "toes" to the characteristic curves for plates $E$

The numbers at the ends of the curves indicate the time of development in minutes. 


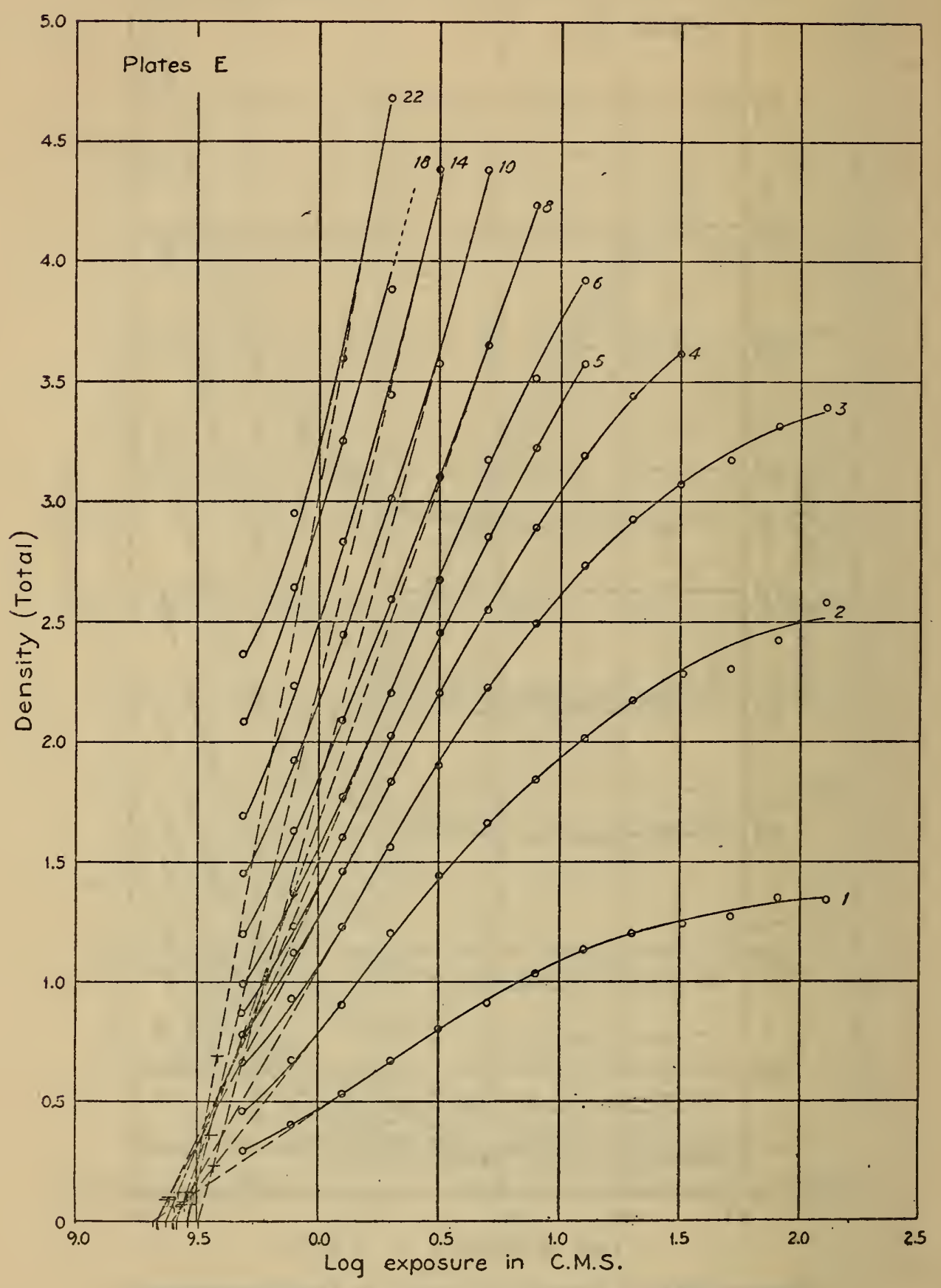

Figure 11.-A family of characteristic curves for plates $E$

The numbers at the endis of the curves indicate the time of development in minutes. 


\section{DISCUSSION OF RESULTS}

\section{CHARACTERISTICS OF THE THREE METHODS}

How the sensitivity as measured by the three methods varies with the time of development is shown in Figures 12 to 16 , respectively.

Referring to Figure 12 for plates $\AA$ (orthochromatic), all three indices show a distinct maximum occurring in the neighborhood of three to four minutes development. However, it is to be noted that the curve for $10 / I$ is distinctly different in shape from the other two, showing a second upward trend. Note that with these plates the curve for $10 / I$ lies above that for $10 / E_{m}$.

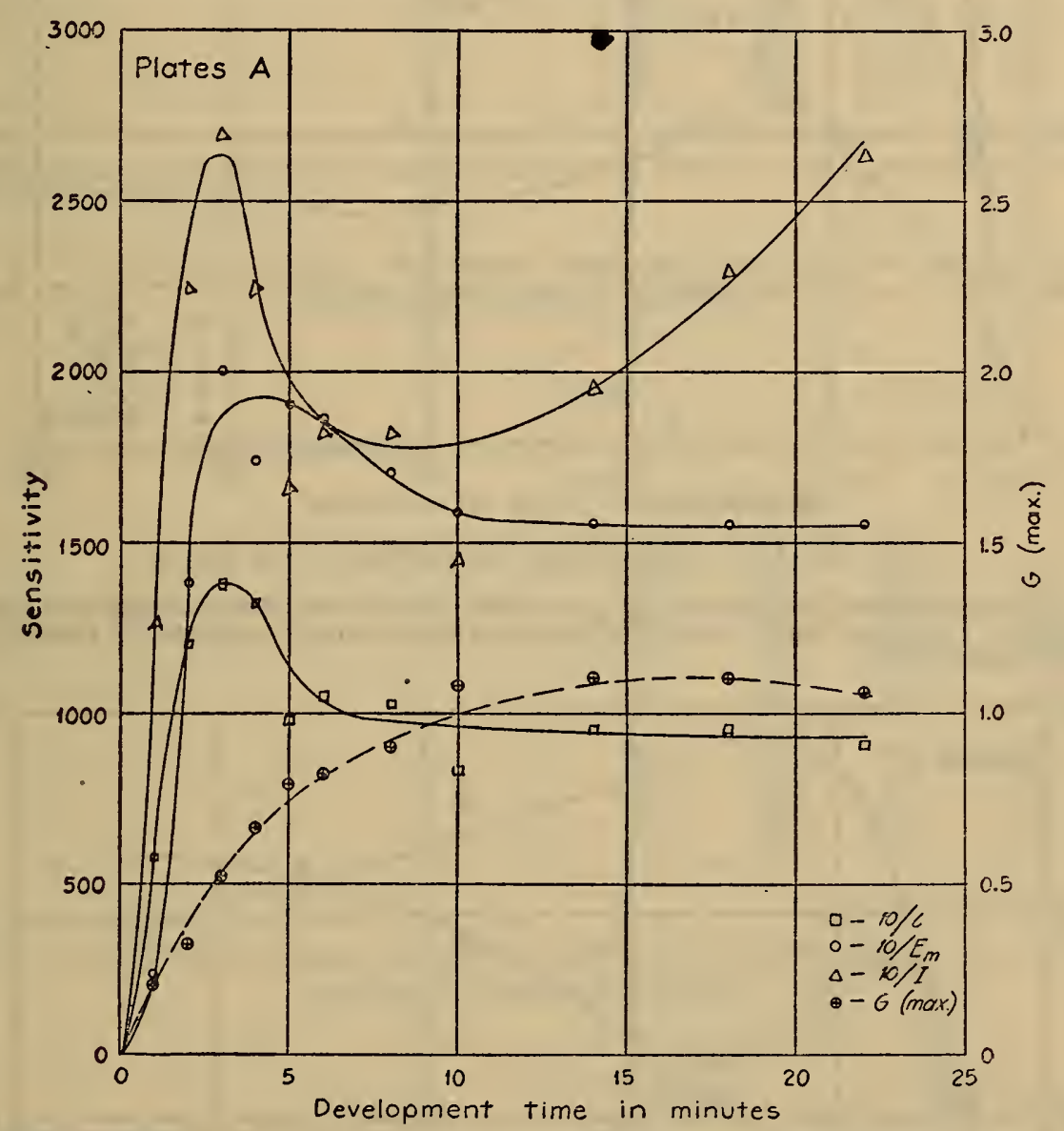

Figure 12.-Sensitivity, development time curves

The solid curves show the variation in each of the three indices with development time for plates $A$. The dashed curve shows the change in the maximum gradient $(G(\max )$.$) with devlopment time.$

In Figure 13 for plates $B$ (ordinary) we again have all indices a maximum at about three to four minutes development. As before, the curve for $10 / I$ is different in shape from the other two.

In Figure 14, plates $\mathrm{C}$ (orthochromatic), similar results were obtained. The curve for $10 / I$ is less different from the other two, but the beginning of a second upward trend is indicated at about 18 minutes development. 


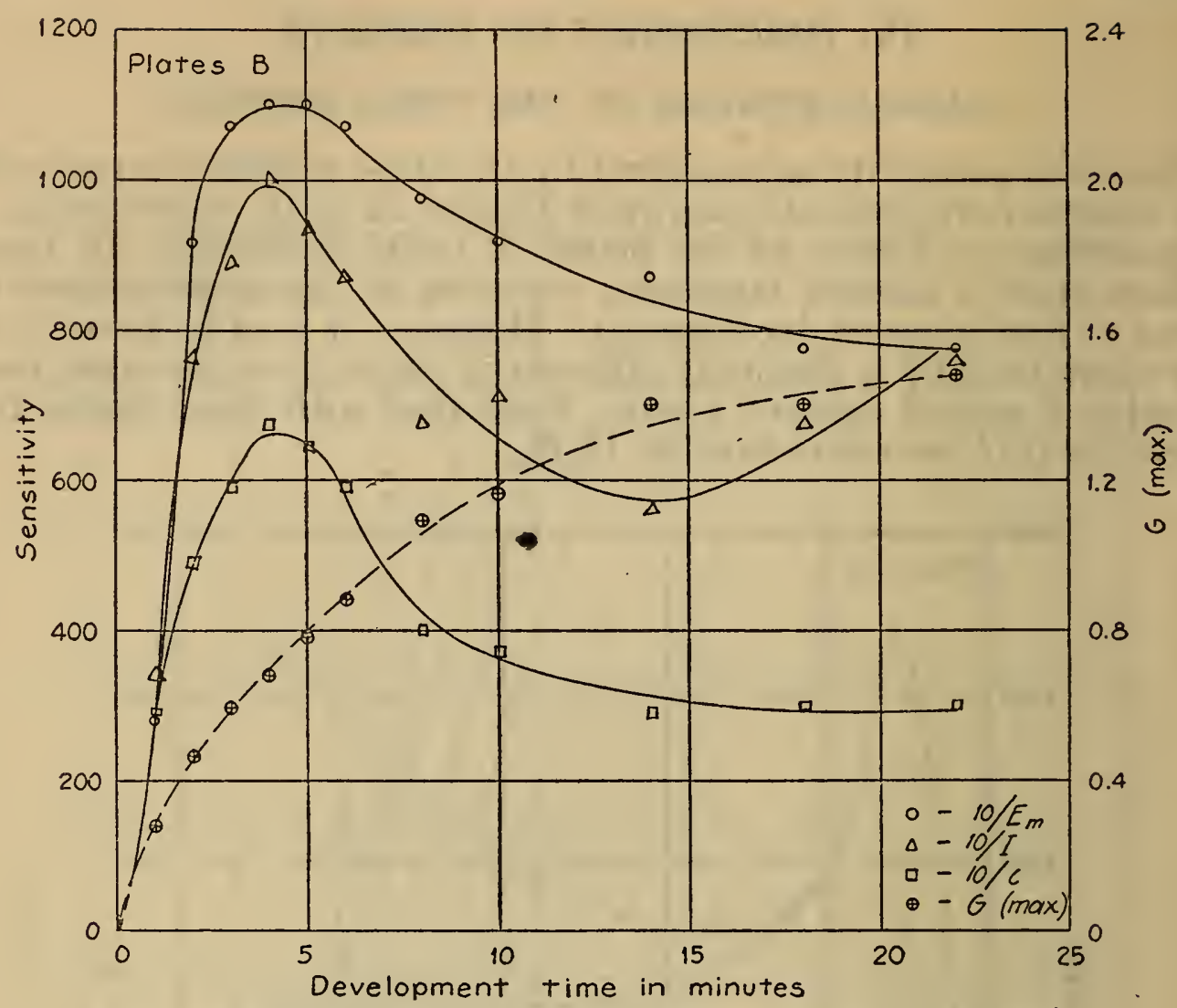

Figure 13.- Sensitivity, development time curves

The solid curves show the variation in each of the three indices with development time for plates $B$. The dashed curve shows the change in the maximum gradient $(G(\max )$.$) with$ development time.

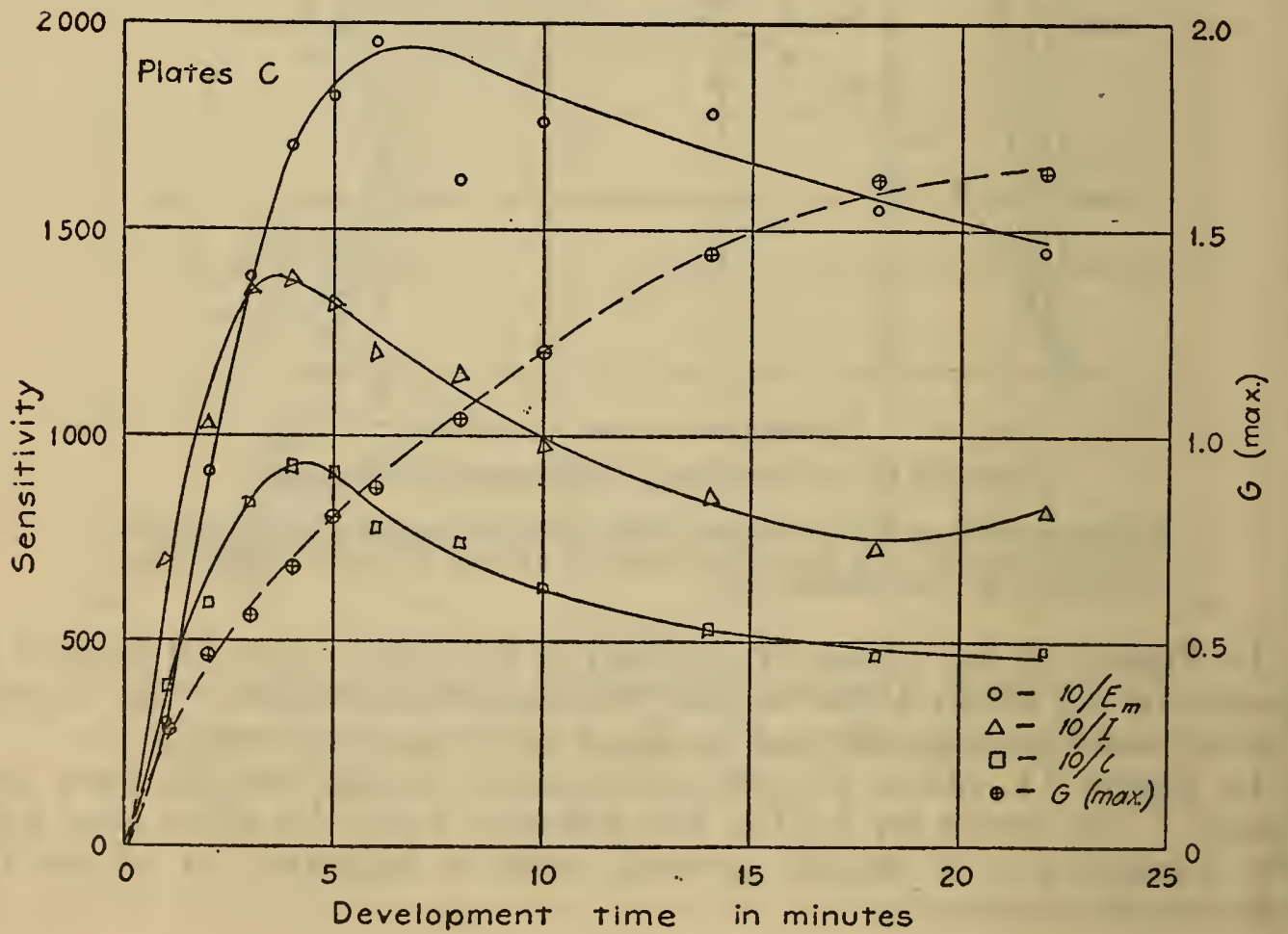

Figure 14.-Sensitivity, development time curves

The solid curves show the variation in each of the three indices with development time for plates $\mathrm{C}$.

The dashed curve shows the change in the maximum gradient $(G(\max )$.$) with development time.$ 
TABLE 5.-Sensitivity indices, maximum gradient, and fog density as functions of development time for plates $D$

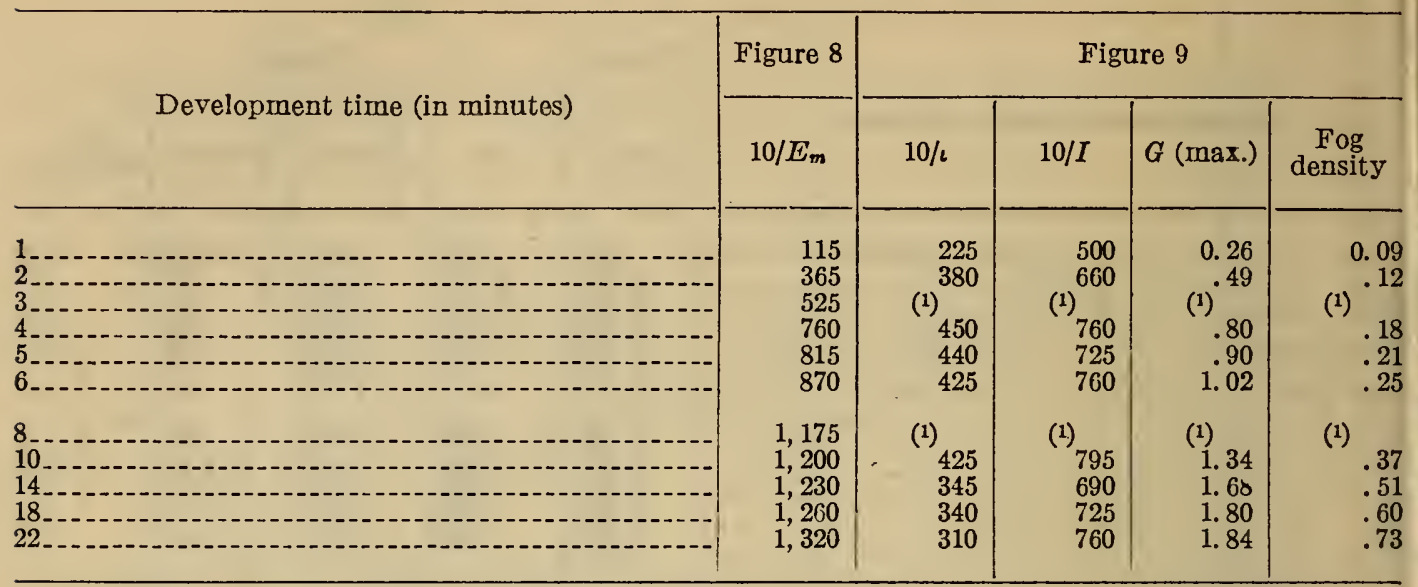

1 Defective test strips.

TABLE 6.-Sensitivity indices, maximum gradient, and fog density as functions of. development time for plates $E$

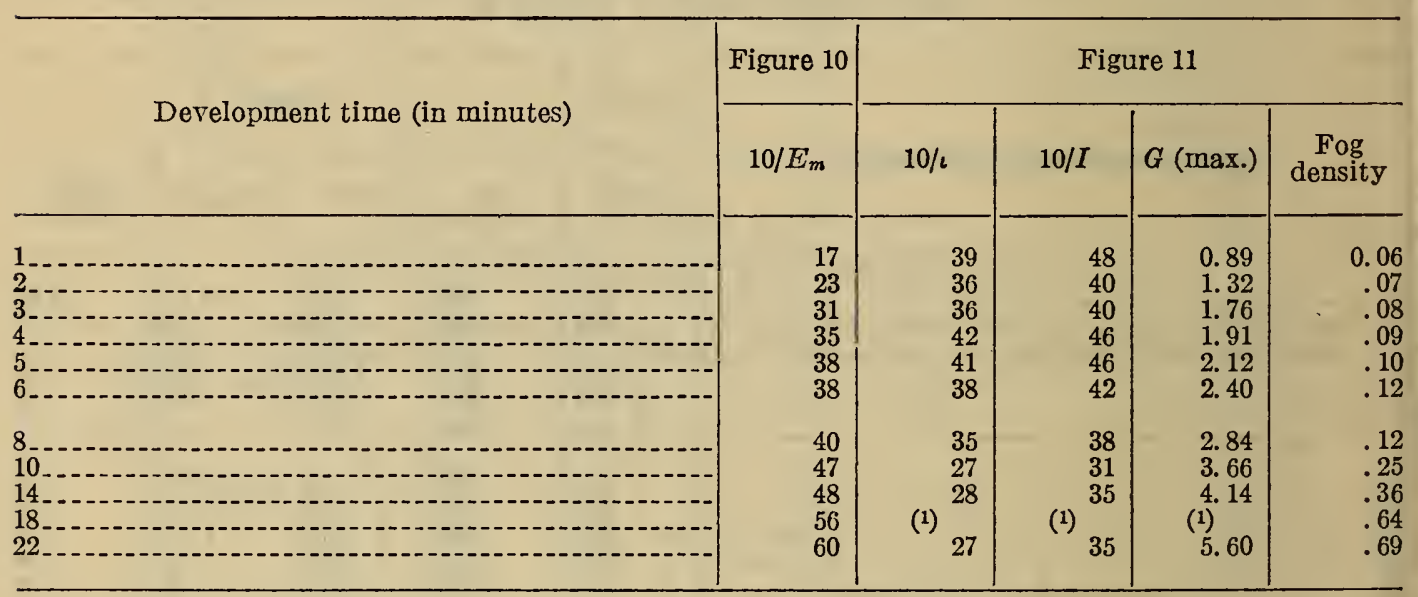

${ }_{1}$ Characteristic curve incomplete.

TABLE 7.-Variation of the sensitivity, development time curve with the value taken as the minimum useful gradient

[The data was obtained from the curves for plates B in fig. 4]

\begin{tabular}{|c|c|c|c|c|}
\hline \multirow{2}{*}{ Developrnent time (in minutes) } & \multicolumn{4}{|c|}{ Values of $10 / E_{m}$ at the gradients indicated } \\
\hline & 0.10 & 0.20 & 0.25 & 0.30 \\
\hline $\begin{array}{l}1 \\
2 \\
3 \\
4 \\
5 \\
6\end{array}$ & $\begin{array}{l}725 \\
1,585 \\
(1) \\
1,585 \\
1,445 \\
1,515\end{array}$ & $\begin{array}{r}280 \\
930 \\
1,070 \\
1,095 \\
1,095 \\
1,070\end{array}$ & $\begin{array}{l}110 \\
645 \\
870 \\
935 \\
910 \\
935\end{array}$ & (1) $\begin{array}{r}515 \\
775 \\
815 \\
830 \\
815\end{array}$ \\
\hline $\begin{array}{l}{ }^{8}{ }^{8} \\
10 \\
14 \\
18\end{array}$ & $\begin{array}{r}1,260 \\
1,200 \\
1,095 \\
975 \\
975\end{array}$ & $\begin{array}{l}975 \\
935 \\
870 \\
775 \\
775\end{array}$ & $\begin{array}{l}870 \\
850 \\
775 \\
710 \\
710\end{array}$ & $\begin{array}{l}795 \\
760 \\
710 \\
660 \\
660\end{array}$ \\
\hline
\end{tabular}

1 Characteristic curve incomplete at this point. 
In Figure 15, plates D (panchromatic), the curves for both $10 / \mathrm{c}$ and $10 / I$ indicate an early maximum which is not shown by the curve or $10 / E_{m}$. The second upward trend of the $10 / I$ curve begins at about 14 minutes development.

In Figure 16, plates $\mathrm{E}$ (process), the curves for both $10 / \iota$ and $10 / I$ ggain indicate an early maximum sensitivity. Note that the $G$ (max.) curve here does not flatten out as it does with the other plates. As with plate $\mathrm{D}$ the curve for $10 / E_{m}$ indicates maximum sensitivity at a time of development in excess of 22 minutes. (Bullock ${ }^{9}$ found the threshold speed for a lantern plate to be a maximum at about 40 minutes development, using another developer.)

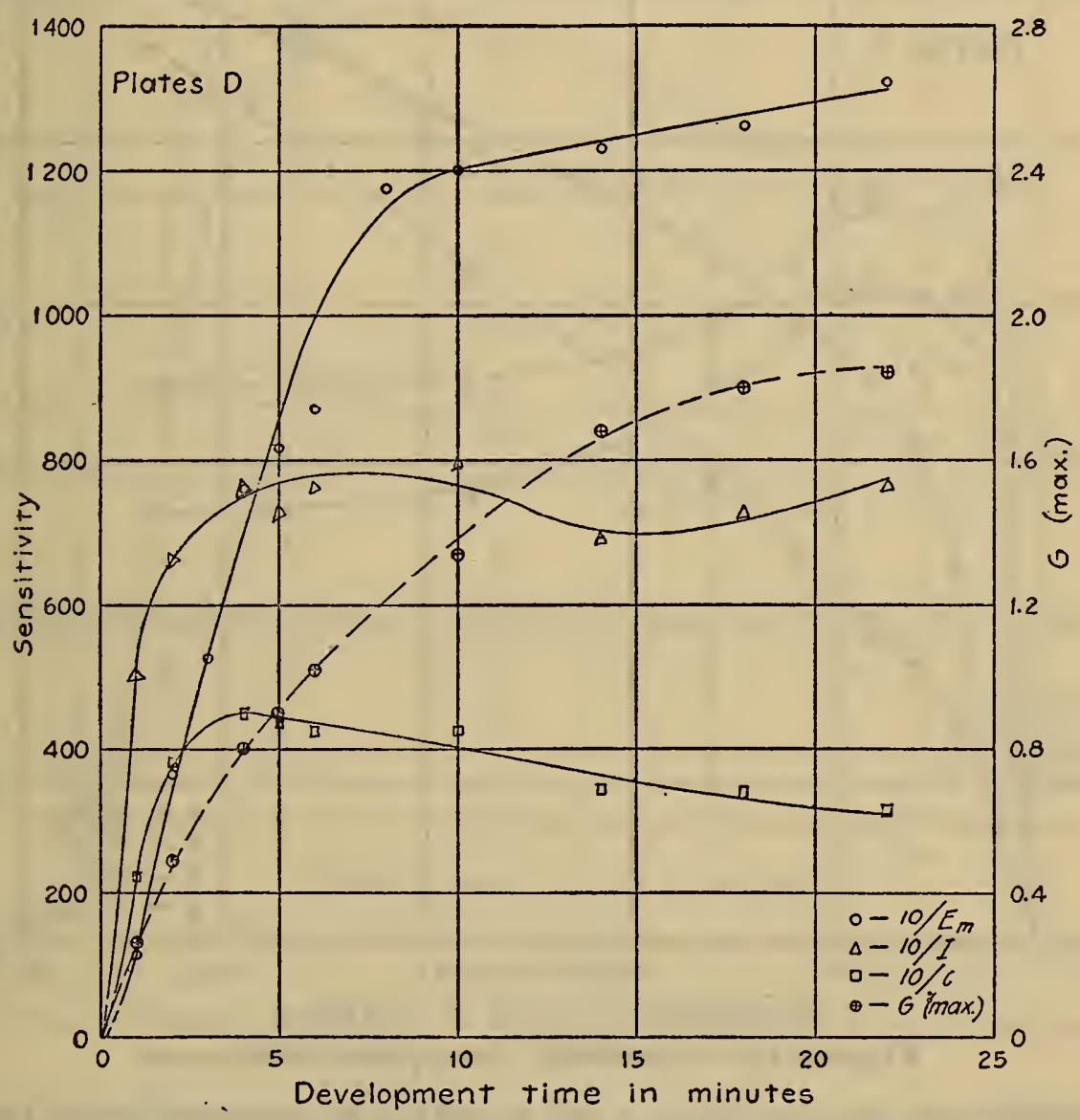

FiguRe 15.-Sensitivity, development time curves

The solid curves show the variation in each of the three indices with development time for plates $\mathrm{D}$. The dashed curve shows the change in the maximum gradient $(G$ (max.)) with development time.

With the exception of the panchromatic and process plates it may be said ${ }^{10}$ that sensitivity increases rapidly to a maximum and then decreases more or less rapidly with further development.

Figures 12 to 16 , inclusive, show that the second upward trend in the $10 / I$ curve usually occurs at about the point where the rate of increase of maximum gradient falls off. ${ }^{11}$ That is, after this point is

\footnotetext{
See footnote 2, p. 496.

10 Other emulsions were tested besides those included in this paper. The results were entirely analagous to those here presented. 11 On all except the process plate, the rate of growth of fog was practically constant over this range of devel-
opment times.
}

$68723-31-7$ 
reached the maximum gradient line tends to shift parallel to itself resulting in an increase in the values of $10 / I$. That this rise does not necessarily signify an actual increase in sensitivity may be seen from the "hypothetical" case discussed in a note ${ }^{12}$ by the authors. In this "hypothetical" case we have two identical characteristic curves, one raised above the other. The straight line portions are, of course, parallel and intersect the zero density line of a total density, log exposure diagram so that the upper curve gives the higher value of $10 / I$. It is obvious that the two emulsions represented by these curves should be considered equally sensitive, since if two negatives were made

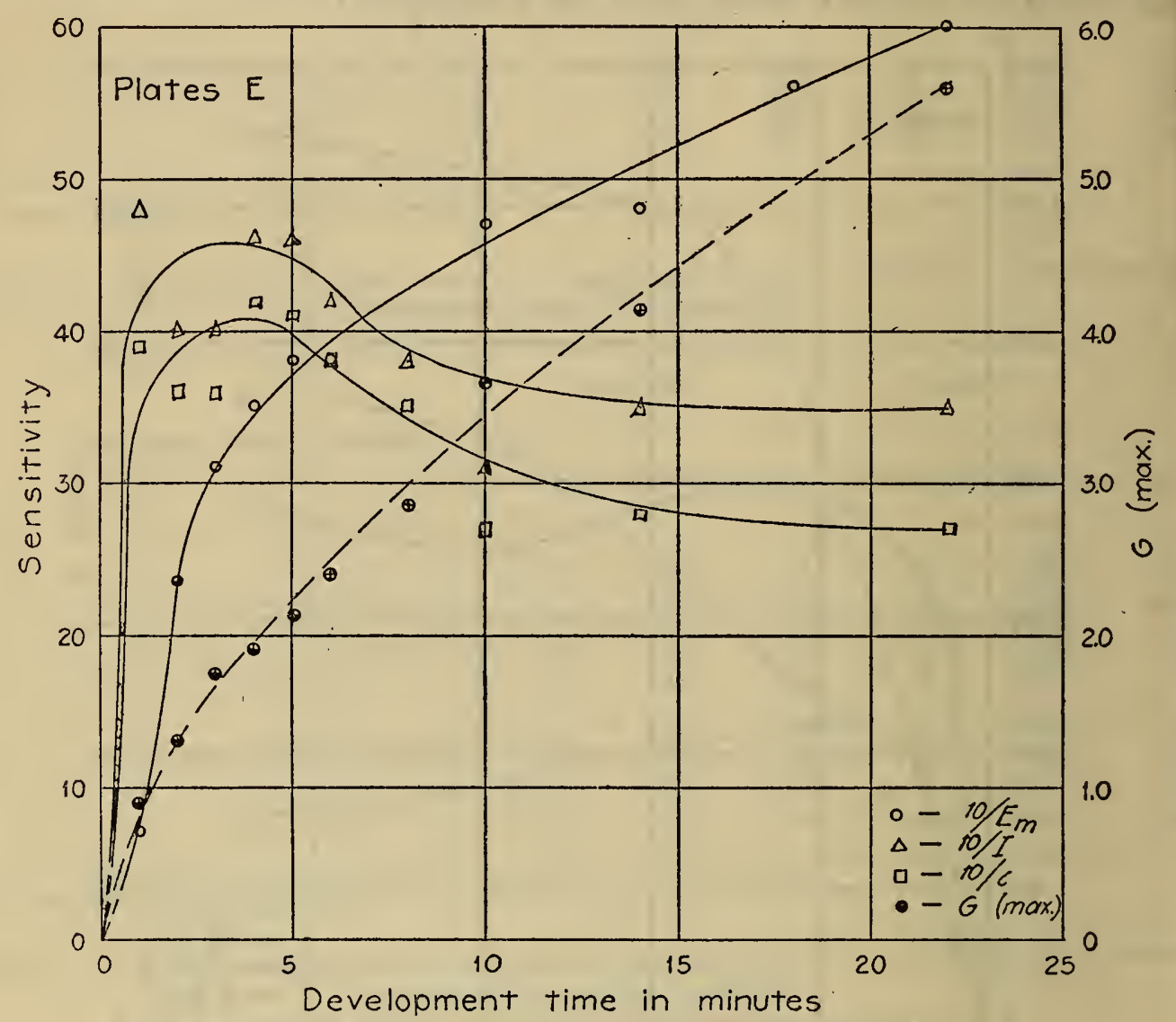

Figure 16.-Sensitivity, development time curves

The solid curves show the variation in each of the three indices with development time for plates $\mathbf{E}$. The dashed curve shows the change in the maximum gradient $(G(\max )$.$) with$ development time.

under the same conditions, one on each emulsion, they would yield (by proper adjustment of the printing exposure) identical positives. The experimental curves strikingly illustrate this objection to the use of $10 / I$.

\section{METHOD OF EXPRESSING RELATIVE SENSITIVITY}

In Figure 17 the sensitivity, development time curves, are plotted for plates $\mathrm{A}, \mathrm{B}, \mathrm{C}$, and $\mathrm{D}$, the index of sensitivity used being $10 / E_{m}$. From this figure the superiority of a sensitivity, development time curve as compared with a single quantity is obvious. The sensitivity

12 Raymond Davis and G. K. Neeland, A Note on the "Speed" of Photographic Emulsions, J. Opt, Soc. Am., July, 1931 . 
of an emulsion having a comparatively flat (sensitivity, development ime) curve can be satisfactorily represented by a single value, while an emulsion having a curve with a pronounced maximum obviously san not. The procedure of some workers of giving indices for three times of development is sufficient in certain cases, provided the times of levelopment are properly chosen. However, an adequate presentation of the difference in sensitivity between emulsions seems to call for their sensitivity, development time curves.

The shape of the curves for emulsions other than the panchromatic or process types shows that where the utmost sensitivity of the plate is

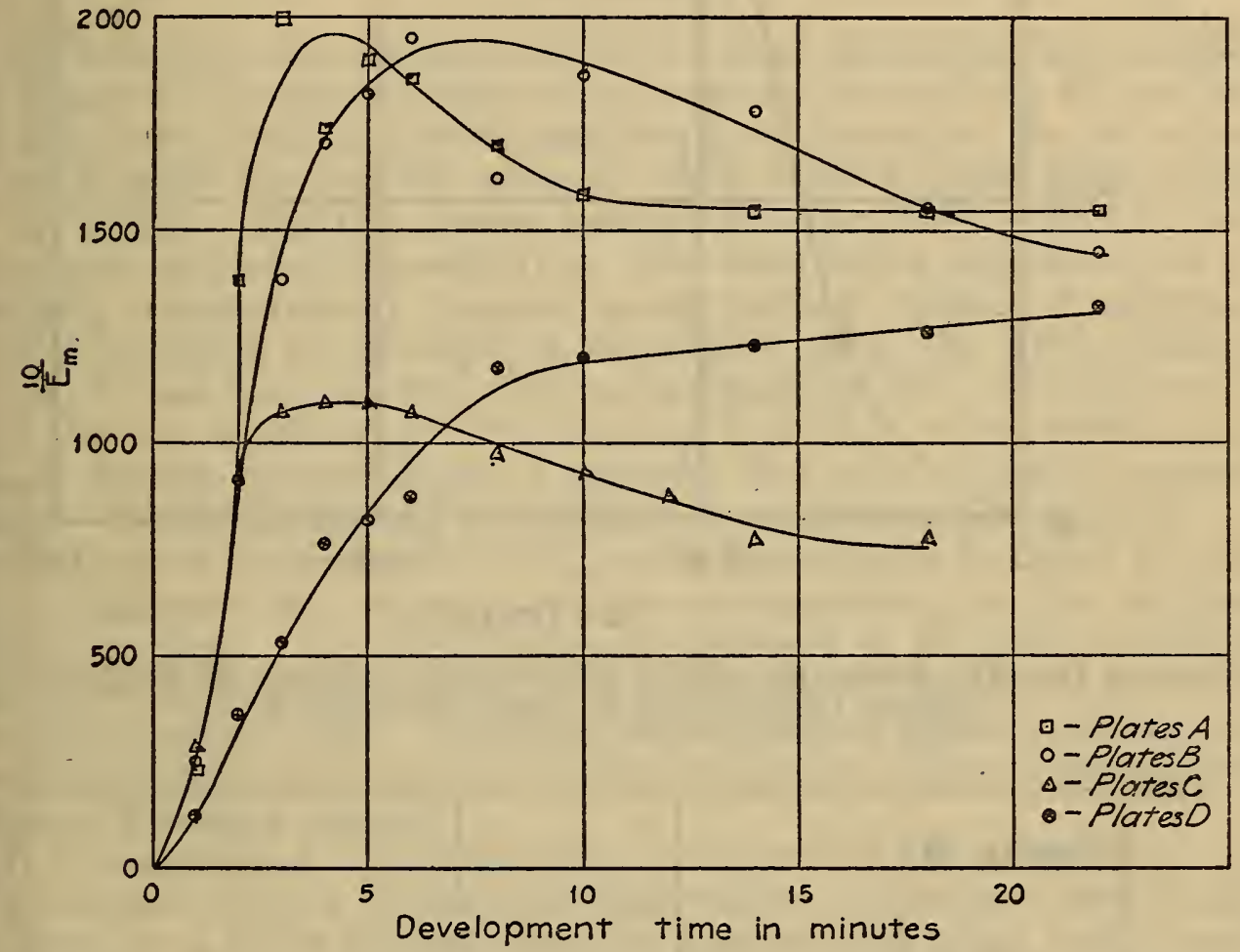

FIGURE 17.-Illustrating the manner of expressing the relative sensitivity of emulsions

All curves are plotted to the same scale. The curve for the process plate $(E)$ is not included as its sensitivity is too low to show to advantage.

required, development should not be carried very far. This is important where it is desired to record very feeble sources.

The relation of sensitivity to contrast is illustrated in Figure 18 where the sensitivity index $10 / E_{m}$ for Plate $\mathrm{B}$ is plotted against maximum gradient. Since Neitz ${ }^{13}$ and others have shown that contrast first increases to a maximum and then decreases with continued development, it will be seen that a sensitivity, maximum gradient curve will be hook shaped if the development is carried sufficiently far (and no correction is made for fog by one of the formulas ${ }^{14}$ for that purpose). In order to avoid such an inconvenient form of expression, sensitivity indices were plotted against time of development, and a curve giving the relation of maximum gradient to development time has been included in Figures 12 to 16 , inclusive.

${ }^{13}$ See footnote 1, p. 496.

"A family of characteristic curves "corrected" for fog by one of these formulas shows contrast increasing to a maximum and then remaining constant with further development. 


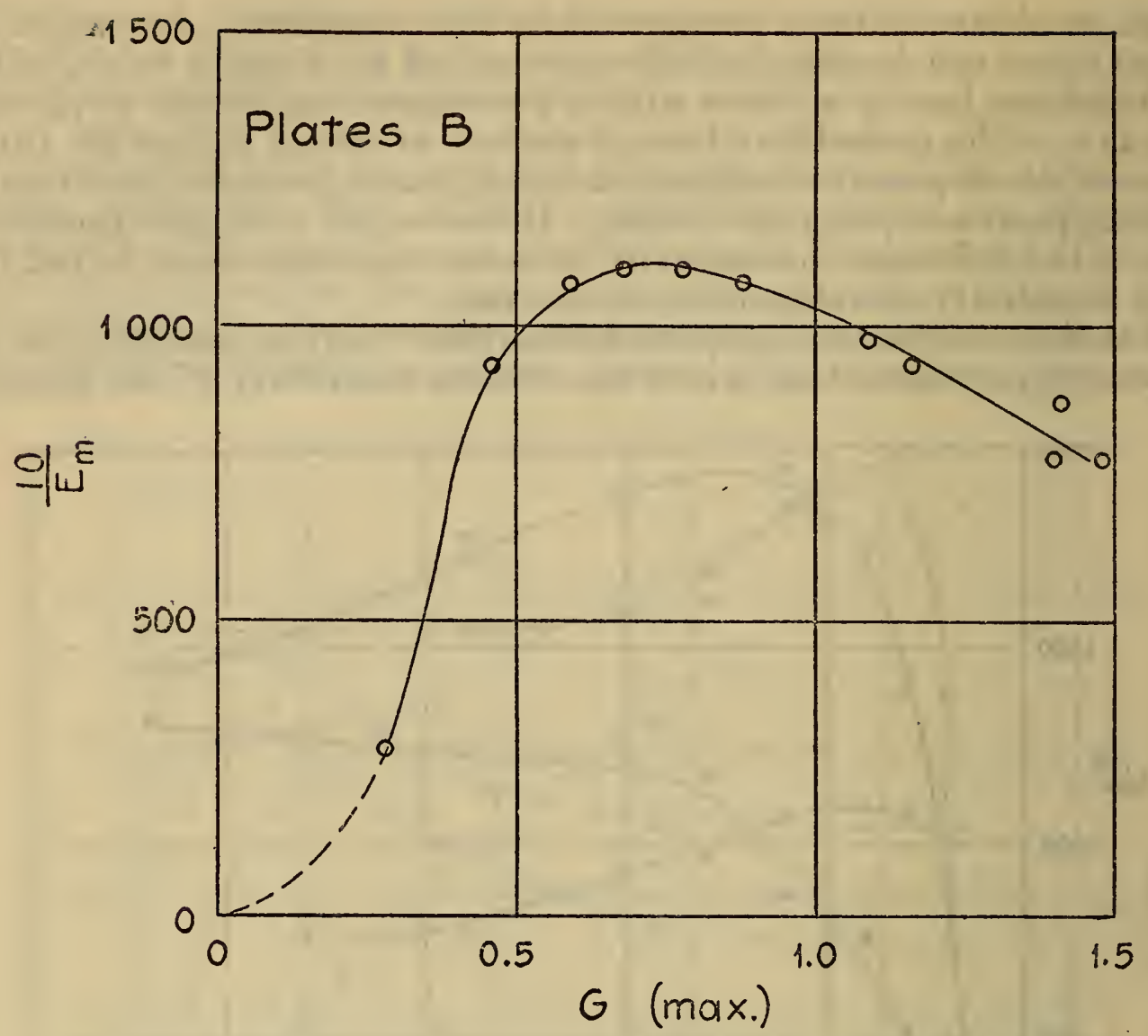

FIGURE 18.-Illustrating the relation of sensitivity (measured by $10 / E_{m}$ ) to contrast (measured by $G$ (max.)) for plates $B$

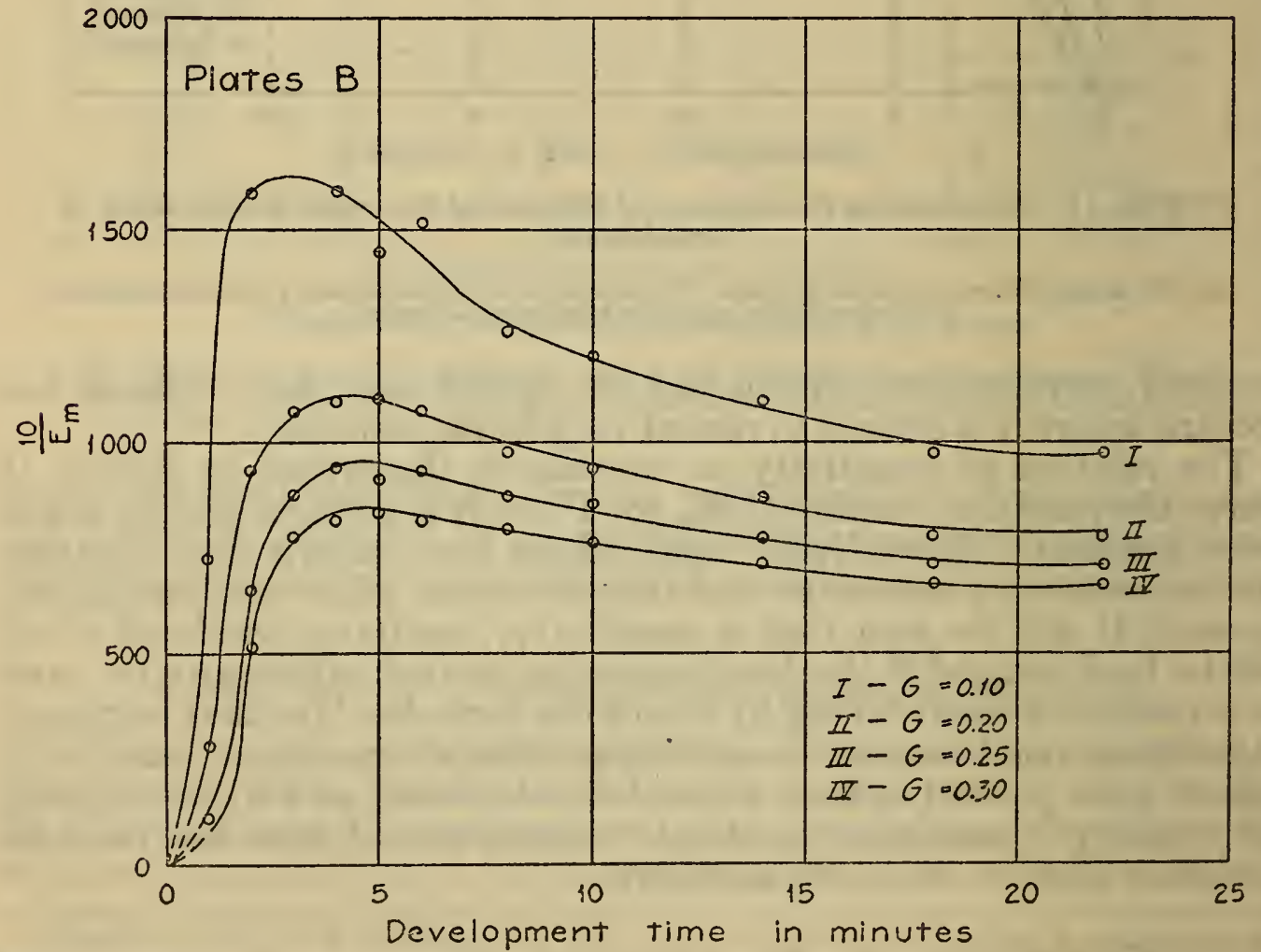

FIgURE 19.-A family of sensitivity, Development time curves $\left(10 / E_{m}\right)$ for plates $B$ showing the effect of change in the value taken as the minimum useful gradient 
The most satisfactory value of gradient to be used in deriving the $10 / E_{m}$ index depends to some extent upon the contrast in the object and the contrast of the positive medium used. The effect of variaion in the value of gradient chosen upon the sensitivity, development ime curve is given in Table 7 for Plates B and illustrated by the family of curves in Figure 19. The curves all show a maximum whose prominence decreases as the value taken as the minimum useful gradient is increased. The development time corresponding to maximum sensitivity increases slightly, but the shape of the curve remains essentially the same.

\section{SUMMARY}

The results of the investigation show that the characteristic curves for many of the photographic emulsions in present use do not have straight line portions of sufficient length to permit of the calculation of the density for a given exposure value over a range great enough to be useful. For this reason neither $10 / \iota$ nor $10 / I$ is entirely satisfactory as an index of sensitivity. The $10 / I$ index appears to be particularly unsatisfactory because when plotted against development time it indicates an increase in sensitivity after the first maximum which, it has been shown, does not actually occur. The indices $10 / \mathrm{c}$ and $10 / i$ are satisfactory for emulsions having a characteristic curve which closely approximates a straight line over a useful exposure range. Their use should be confined to emulsions of this type.

For general purposes the $10 / E_{m}$ index seems to be the most practical as it indicates the exposure value corresponding to the minimum useful gradient. The best value of gradient to be used in deriving this index depends somewhat on the contrast of the object and of the positive medium used. However, when plotted against development time this index gives curves of similar shape for wide variations in the value of gradient selected.

It is considered unsatisfactory to represent the sensitivity of a given emulsion by a single numerical value. A better representation is given by a curve plotted between a sensitivity index and development time. For work not requiring the greatest accuracy, however, values of the index for at least three development times may be satisfactory provided the development times are properly chosen.

Washington, June 13, 1931. 